\title{
SALA DE AULA INVERTIDA: \\ INVESTIGAÇÃO SOBRE O GRAU DE FAMILIARIDADE CONCEITUAL TEÓRICO-PRÁTICO DOS DOCENTES DA UNIVERSIDADE'
}

\author{
FLIPPED CLASSROOM: \\ INVESTIGATION ABOUT THE DEGREE OF FAMILIARITY OF THEORETICAL- \\ PRACTICAL CONCEPTS FROM UNIVERSITY TEACHERS
CLASE AL REVÉS:
INVESTIGACIÓN SOBRE EL GRADO DE FAMILIARIDAD CONCEPTUAL TEORICO Y PRÁCTICO DE LOS DOCENTES DE LA UNIVERSIDAD

Elieser Xisto da Silva Schmitz ${ }^{2}$, Susana Cristina dos Reis ${ }^{3}$

\section{RESUMO}

Este artigo apresenta resultados da investigação da aproximação conceitual teórico-prática entre a abordagem da sala de aula invertida e os saberes e fazeres de docentes da Universidade Federal de Santa Maria, mediante a disponibilização de material didático instrucional. 0 estudo descritivo e exploratório, de natureza qualiquantitativa, descreve o grau de familiaridade com a temática e as necessidades de formação identificadas pelos participantes, que ocorreu por meio da aplicação de Teste Conceitual (TC) e de questionário. Os resultados apontam compreensão dos conceitos apresentados e identificação de aspectos de inversão da sala de aula de forma parcial nas práticas docentes, embora a estratégia não fosse conhecida pela maioria. Além disso, o levantamento de necessidades identificou interesse por formação na área de metodologias ativas de aprendizagem e ensino híbrido. Para aplicação da sala de aula invertida, os métodos que despertaram maior interesse foram o Just-in-Time Teaching (Ensino sob Medida) e o Peer Intruction (Instrução por Pares). Já em termos de tecnologias, houve destaque para a lousa digital interativa e para softwares de edição de áudio/vídeo e de captura de tela.

PALAVRAS-CHAVE: Sala de aula invertida. Ensino híbrido. Metodologias ativas de aprendizagem.

\begin{abstract}
This paper presents results of an investigation between the theoretical-practical flipped classroom approach and the knowledge and actions of university teachers through the availability of instructional didactic material. It is a quantitative and quantitative exploratory study that describes the degree of familiarity with the theme and the necessity of continuing education identified by the participants, which occurred by the application of a conceptual test and questionnaire. The results point out an understanding of the presented concepts, and a
\end{abstract}

\footnotetext{
${ }^{1}$ Este trabalho é parte da pesquisa desenvolvida por Schmitz (2016) , em dissertação apresentada no Programa de Pós-Graduação Profissional em Tecnologias Educacionais em Rede, da Universidade Federal de Santa Maria, em 13/12/2016.

${ }^{2}$ Mestre em Tecnologias Educacionais em Rede - Universidade Federal de Santa Maria (UFSM) - Santa Maria RS. Brasil. Técnica em Assuntos Educacionais - Equipe de Capacitação do Núcleo de Tecnologia Educacional (NTE) Universidade Federal de Santa Maria (UFSM) - Santa Maria - RS. Brasil. E-mail: xelieser@cead.ufsm.br ${ }^{3}$ Doutorado em Letras - Universidade Federal de Santa Maria (UFSM) - Santa Maria - RS. Brasil. Professora adjunto 4 - Curso de Letras da Universidade Federal de Santa (UFSM) - Universidade Federal de Santa Maria (UFSM) - Santa Maria - RS. Brasil. Pesquisadora e orientadora do Programa de Mestrado Profissional de Tecnologia Educacionais em Rede - Universidade Federal de Santa Maria (UFSM) - Santa Maria - RS. Brasil. E-mail: suzireis@cead.ufsm.br
}

Submetido em: 10/01/2017 - Aceito em: 20/07/2017

(C) ETD- Educação Temática Digital Campinas, SP $\quad$ v.20 $\quad$ n.1 $\quad$ p. 153-175 jan./mar.2018


partial understanding about the flipped classroom aspects among the teaching practices, as most of the participants did not know well this teaching strategy. In addition, the needs survey identified the interest in continuing education about teacher's active learning and blended methodologies. The approaches that aroused most interest of the participants during a flipped classroom class were Just-in-Time Teaching and Peer Instruction. In relation to the technological tools to be used in class, the results found out that the interactive whiteboard as well as the audio/video editing and screen capture software are the mainly tools interest of the audience.

KEYWORDS: Flipped classroom. Blended learning. Active methodologies of learning.

\section{RESUMEN}

En este artículo se presentan los resultados de investigación sobre los aspectos conceptuales, teórico y práctico, entre el modelo de la clase invertido y los conocimientos y prácticas de los docentes de la Universidade Federal de Santa Maria, por medio de la disponibilización de material didáctico. El estúdio descriptivo, de naturaleza cualitativa y cuantitativa, describe el grado de familiaridad de los participantes con el tema, así como las necesidades de formación identificadas por ellos en la prueba conceptual y en el cuestionario. Los datos muestran la comprensión de los conceptos presentados y la identificación por los profesores de características parciales de la clase al revés en sus prácticas de enseñanza, aunque la mayoría no la conocia. Por otro lado, las necesidades por formación apuntadas han sido las metodologías activas de aprendizaje y la enseñanza híbrida. A los efectos de los métodos para mezclarse con el aula invertida los que han despertado mayor interés fueron el Just-in-Time Teaching o justo a tiempo y el Peer Instruction o instruccíon por pares. En términos de tecnologia para invertir la clase, a los profesores les gustaría aprender a utilizar la pizarra interactiva y softwares de edición de audio y video y de captura de pantalla.

PALABRAS CLAVE: Clase invertida. Enseñanza híbrida. Metodologías activas de aprendizaje.

\section{INTRODUÇÃO}

Estudos recentes na área da Educação e Tecnologias Educacionais têm sugerido a necessidade urgente do desenvolvimento de práticas pedagógicas inovadoras e uso de metodologias ativas em sala de aula (KENSKI, 2013; VALENTE, 2014; MORAN, 2015; LOPES, 2015). Diante desse cenário, a estratégia da Sala de Aula Invertida (SAI) ou Flipped Classroom (FC) é um modelo que tem chamado a atenção de vários pesquisadores, já que tem suas origens no ensino híbrido (blended learning ou b-learning) e pode potencializar novas abordagens na prática de ensino, especialmente, no ensino superior.

Entende-se por ensino híbrido "uma combinação dos recursos e dos métodos usados face a face e online, com a qual se procura tirar partido das vantagens de qualquer um dos dois sistemas de aprendizagem" (MIRANDA, 2005, p. 48). Seguindo essa mesma concepção, Christensen, Horn e Staker (2013, p. 27) ao analisarem os programas de educação formal que combinam o ensino online com o ensino presencial, identificaram modelos de implementação do ensino híbrido na educação básica norte-americana, situando a sala de aula invertida como um modelo rotacional de ensino, "no qual a rotação ocorre entre a prática presencial supervisionada pelo professor (ou trabalhos) na escola e a residência ou outra localidade fora da escola para aplicação do conteúdo e lições online".

Nessa perspectiva, inverter a sala de aula significa transferir eventos que eram feitos em aula para fora da sala de aula (LAGE, PLATT; TREGLIA, 2000). Assim, "inverter" tem a ver

$\begin{array}{llllll}\text { (c) ETD- Educação Temática Digital Campinas, SP } & \text { v.20 } & \text { n.1 } & \text { p.153-175 } & \text { jan./mar.2018 }\end{array}$


com o fato de fazer em aula o que era feito em casa - resolver problemas - e de fazer em casa, o que era feito em aula - assistir a palestras expositivas, por exemplo (BERGMANN; OVERMEYER; WILIE, 2013). Segundo conteúdo elaborado pela junta diretiva da Flipped Learning Network (2014), aprendizagem invertida pode ser reconhecida ainda como uma abordagem pedagógica, na qual a aula expositiva passa da dimensão da aprendizagem grupal para a dimensão da aprendizagem individual, de modo a transformar o espaço em sala de aula em um ambiente de aprendizagem dinâmico e interativo, permitindo ao professor, como mediador, guiar a aplicação dos conceitos. Ao recorrer a essa estratégia, o professor dispõe de mais tempo em aula para interagir com os alunos e assim propor atividades mais elevadas de trabalho cognitivo tais como aplicar, analisar, avaliar e criar. Nesse contexto, a reestruturação do tempo em sala de aula e o replanejamento das atividades mudam os papéis do professor e do aluno: o educador passa a ser um guia/tutor para fornecer sugestões de especialista, deixando de ser o "sábio no palco" para ser um orientador; já o aluno assume maior responsabilidade sobre o seu próprio aprendizado, pois precisa se preparar para as aulas, estudando e enviando perguntas sobre os conteúdos disponibilizados previamente (BERGMANN; OVERMEYER; WILIE, 2013; BACICH; TANZI NETO; TREVISANI, 2015; BERGMANN; SAMS, 2016).

Segundo Bergmann e Sams (2016), a inversão tem mais a ver com a mentalidade de deslocar a atenção do professor para o aluno e para a aprendizagem, característica em comum entre todas as formas de inversão, ou seja, o foco deve ser o aluno. Para favorecer essa prática, os autores usam vídeos no lugar da instrução direta e afirmam que são as interações e as atividades significativas propostas durante o tempo face a face as mais importantes. Os primeiros minutos de aula são dedicados a responder dúvidas e a esclarecer equívocos de compreensão dos alunos sobre o conteúdo entregue previamente, antes dos conceitos serem praticados e aplicados incorretamente. O tempo restante é usado para atividades práticas (hands on, que envolvem "mão na massa") mais extensas e/ou resolução de problemas dirigidos (Figura 1). O processo, como salienta Ramal (2015, p. 2) "é permeado por avaliações para verificar se o aluno leu os materiais indicados, se é capaz de aplicar conceitos e se desenvolveu as competências esperadas". 


\section{SALA DE AULA INVERTIDA}

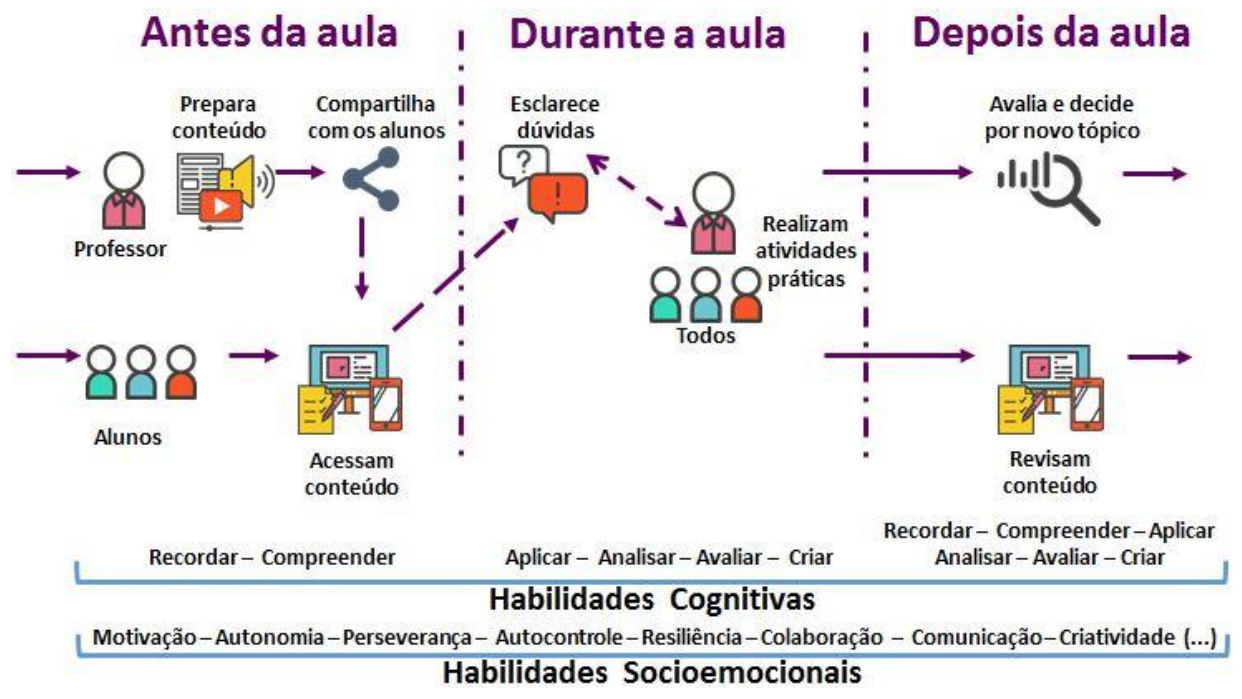

FIGURA 1 - Esquema básico da sala de aula invertida.

Fonte: Schmitz (2016, p. 67)

Para O'Flaherty e Phillips (2015), a adoção do modelo retira ambos (aluno e professor) de suas zonas de conforto, pois as atividades de baixa cognição, antes providas pelo docente, em sala de aula, passam para a responsabilidade do aluno, que deve administrá-las em seu tempo pessoal. A preparação pelo professor de conteúdos para a préaula, bem como de atividades de alta cognição para a aula e de atividades de sedimentação e avaliação, torna-se mais complexa. Além disso, as atividades de aula, agora focadas em aplicação do conhecimento adquirido nas leituras antecipadas e na resolução de problemas, exigem do educador flexibilidade e criatividade para identificar erros ou lacunas de conhecimento, a fim de saná-las de forma individual ou coletiva em tempo de execução.

O uso desse modelo pedagógico na Educação não é recente, muitos professores já devem ter invertido suas salas de aula ao pedir que alunos lessem um texto, assistissem a um vídeo ou resolvessem problemas antes das aulas, no entanto, para se engajar na aprendizagem invertida é preciso que os professores incorporem quatro pilares fundamentais em suas práticas, que são: criar um ambiente flexível que envolva uma diversidade de estilos de aprendizagem; incorporar uma cultura de aprendizagem centrada no aluno; pensar conteúdos dirigidos, de modo a definir o que eles precisam ensinar e o que os alunos podem explorar por conta própria; ser um educador facilitador, oferecendo atendimento contínuo e feedback imediato (FLIPPED LEARNING NETWORK, 2014).

Para Teixeira (2013, p. 13), apesar de o conceito existir há mais de uma década, só nos últimos anos é que as tecnologias e respectivas aplicações evoluíram para que fosse "mais acessível, praticável e democrático". Por outro lado, como observa Ramal (2015), a

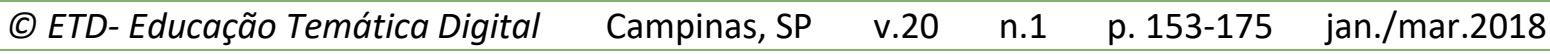


abordagem da sala de aula invertida vem se tornando uma tendência crescente também em países como Finlândia, Singapura, Holanda e Canadá, que têm alto desempenho em educação.

Tendo em vista discutir sobre como a sala de aula invertida tem sido aplicada no ensino superior, este artigo apresenta resultados da investigação da aproximação conceitual teórico-prática sobre a temática sala de aula invertida e os saberes e fazeres de docentes da Universidade Federal de Santa Maria, mediante a disponibilização de material didático instrucional aos docentes da instituição. O estudo proposto adotou uma metodologia descritiva e exploratória, de natureza qualiquantitativa e descreve o grau de familiaridade com a temática e as necessidades de formação identificadas pelos participantes, que ocorreu por meio da aplicação de Teste Conceitual (TC $)^{4}$ e de questionário. Para isso, na sequência, descrevem-se os pressupostos teóricos sobre a abordagem da sala de aula invertida, a metodologia adotada para coleta e análise dos dados e, por último, as considerações finais para este artigo.

\section{Sala de Aula Invertida: surgimento e pressupostos teóricos}

De acordo com mapeamento teórico realizado por Schmitz (2016), na década de 1990, Mazur propôs o método Peer Instruction (PI), que consiste na disponibilização de materiais aos alunos para estudo antes das aulas, para em classe, o professor instigar discussões entre os pares e aplicar testes conceituais (ARAUJO; MAZUR, 2013). Em 1999, Gregor Novak e outros defenderam o Just-in-Time Teaching (JiTT), método que consiste em ajustar a aula às necessidades dos alunos, diagnosticadas por meio da leitura das respostas dos alunos sobre determinado conteúdo um pouco antes das aulas (NOVAK et al., 1999). Em 2000, o conceito de $F C$ foi apresentado por J. Wesley Baker. No mesmo ano, Lage, Platt e Treglia publicaram um artigo com resultados positivos sobre a utilização do modelo em uma disciplina de Microeconomia, em comparação a outra disciplina de mesmo conteúdo, ministrada na forma tradicional, e denominaram-no Inverted Classroom (LAGE; PLATT; TREGLIA, 2000, p. 41).

Em 2004, Salman Khan gravou aulas em vídeo, a pedido da prima, produzindo materiais e publicando na internet, fundando a Khan Academy, que disponibiliza videoaulas sobre os mais variados assuntos. Esse evento contribuiu para a divulgação da ideia da sala de aula invertida, porém representa apenas uma das diversas maneiras de implementar esse conceito e inverter a sala de aula, segundo afirma Sams (2011). Em 2006 e 2007, Aaron

\footnotetext{
${ }^{4}$ O Teste Conceitual (TC) foi elaborado por três questões fechadas de múltipla escolha de compreensão do conteúdo e uma questão aberta sobre dúvidas e/ou dificuldades de entendimento do conteúdo, tendo por referência a metodologia Peer Instruction (MAZUR; WATKINS, 2009) para elaboração das questões.
}

$\begin{array}{llllll}\text { (C) ETD- Educação Temática Digital } & \text { Campinas, SP } & \text { v.20 } & \text { n.1 } & \text { p. 153-175 } & \text { jan./mar.2018 }\end{array}$


Sams e Jonathan Bergmann, inspirados em atender às necessidades dos alunos, passaram a gravar aulas, usando software de captura de tela (screencast) que gravava apresentações em powerpoint. Os autores se tornaram grandes divulgadores da sala de aula invertida nos EUA e em vários países, inclusive, no Brasil (SAMS, 2011; BERGMANN; SAMS, 2016; SCHMITZ, 2016).

Ao buscar resposta à questão sobre quais aspectos-chave da abordagem contribuem para a sua eficácia e um melhor aprendizado para o aluno no ensino superior, O'Flaherty e Phillips (2015), em uma scoping review ${ }^{5}$, concluíram que existe uma grande lacuna de estudos comparativos entre a sala invertida e a tradicional, não havendo evidência robusta sobre a superioridade de uma abordagem sobre a outra. O estudo, segundo os autores, apontou para dois pontos principais que, juntos, podem constituir a questão-chave do método: (i) o engajamento de alunos e professores; e (ii) o modelo conceitual usado para desenhar uma sala de aula invertida.

O’Flaherty e Phillips (2015) sugerem que a transferência de conteúdo e o engajamento dos alunos são aspectos mais importantes do que os recursos usados para inverter a sala de aula e dividem as tecnologias usadas em "atividades assíncronas préclasse" (podcasts, vodcasts, screencasts, anotações e captura de vídeos e, como recursos adicionais, sistemas de tutoria automatizada, guias de estudo e vídeos interativos de repositórios online) e "atividades síncronas face a face" (smartphones, tablets e questionários eletrônicos do tipo quiz - individuais ou pareados).

Entre as tecnologias referidas pelos professores, nas experiências relatadas no C21U'S Guide to Flipping Your Classroom, a videoaula é predominante, porém duram menos de cinco minutos e agregam outras tecnologias para assumirem um formato multimídia, tais como sumários de navegação rápida, que permitem ao aluno decidir quais pontos quer reforçar ou ignorar; questionários interativos, que possibilitam ao professor desafiar o aluno e apontar os pontos mais importantes do assunto; referências, na forma de hipertexto (hiperlinks), para fontes complementares. Outros recursos citados foram fóruns colaborativos, wikis editáveis e questionários de autoavaliação e avaliação entre pares, a maioria dessas ferramentas presentes em plataformas de ensino, como o Moodle. Independentemente da tecnologia utilizada, o sucesso da inversão da sala de aula reside em como essas tecnologias são utilizadas e combinadas. Para tanto, devem ser levadas em

\footnotetext{
${ }^{5}$ Revisão de escopo equivale à revisão de mapeamento, diferenciando-se da revisão sistemática nos seguintes aspectos: responde a várias questões de pesquisa; apresenta um levantamento mais abrangente de todo contexto de estudo, pois considera também artigos de opinião; é menos focada, porque a intenção é cobrir a literatura disponível. Além disso, na etapa de análise, é incomum a inserção de técnicas de meta-análise e sínteses narrativas, e a revisão de escopo traz representações gráficas de distribuição de estudo por tipo de classificação nos resultados (ANDRADE; LOBATO, 2010).
}

(C) ETD- Educação Temática Digital Campinas, SP $\quad$ v.20 $\quad$ n.1 $\quad$ p. 153-175 jan./mar.2018


consideração questões como: criatividade do professor, minimização do tempo do professor para produzir o material (usar novidades, mas de forma gradativa, dando preferência para as tecnologias que melhor domine) e minimização do tempo de acesso do aluno (FLIPPED, [201-]; MARGULIEUX; MAJERICH; MCCRACKEN, 2013).

Moran (2015) considera a SAI como um dos modelos mais interessantes para mesclar tecnologia com metodologia de ensino, pois concentra, no virtual, o que é informação básica e, na sala de aula, atividades criativas e supervisionadas, uma combinação de aprendizagem por desafios, projetos, problemas reais e jogos. Bergmann e Sams (2016, p. 45) afirmam que a abordagem "é compatível com a aprendizagem baseada em projetos", "aprendizagem por descoberta", "induzida pelo interesse do aluno". A integração entre métodos pode ser encontrada em estudos realizados por Mazur e Watkins (2009) e Araujo e Mazur (2013) e Oliveira, Veit e Araujo (2015) que, embora não tenham feito relação com a sala de aula invertida, apresentam propostas que consistem em incentivar a adoção de um modelo para valorizar o tempo em aula, destinando-o para a aprendizagem ativa de conteúdos, em vez de usar o período em classe para transmitir informações presentes em livros/textos.

Para Prensky (2007), os professores ainda usam para ensinar os mesmos métodos pelos quais aprenderam, porém os alunos não se encaixam no sistema que foi projetado para ensiná-los. Nesse sentido, Lopes $(2015$, p. 6) observa que "o jeito de aprender mudou", o que falta é expandir a mente daqueles que ensinam para novas práticas pedagógicas apoiadas por TIC.

Além disso, a Organização de Cooperação e Desenvolvimento Econômico ${ }^{6}$ (OCDE) tem posto em prática um projeto de governança educacional global, de modo a fomentar na educação de crianças e de jovens o desenvolvimento das habilidades socioemocionais, pois a posição de organismos multilaterais como a OCDE é a de que colaboração, comunicação, motivação, negociação, autonomia, perseverança, autocontrole, resiliência e criatividade são habilidades essenciais à formação profissional, para que os jovens obtenham sucesso em um mercado de trabalho em permanente mudança (RODRIGUES, 2015).

Assim, considerando as discussões apresentadas pelos autores supracitados, a chave para promover o engajamento dos estudantes durante a aula é que haja mudanças nas atividades, sejam estas exposições orais curtas, intercaladas com outras atividades individuais ou colaborativas, exercícios de fixação, trabalhos em laboratórios, etc. Essa variedade permite que o aluno renove a sua atenção a cada mudança e, também, pratique o uso de novos conceitos estudados. Além disso, após as aulas, os estudantes podem receber

\footnotetext{
${ }^{6}$ Do original em inglês: Organization for Economic Co-operation and Development - OECD.
}

(C) ETD- Educação Temática Digital Campinas, SP $\quad$ v.20 $\quad$ n.1 $\quad$ p. 153-175 jan./mar.2018


outros tipos de questões para responder eletronicamente, em forma de desafios, relacionados ao conteúdo trabalhado em aula e que instiguem questionamentos com base em um contexto diverso.

Para sintetizar como toda essa teoria pode ser colocada efetivamente em prática, a Figura 2 apresenta um ponto de vista para a combinação do modelo da sala de aula invertida com metodologias ativas de aprendizagem, considerando um ambiente de ensino diferenciado, ou seja, um ambiente flexível, com assincronicidade de ações, dentro de um caos controlado e adaptado às necessidades do aluno, em que se preconiza não só o desenvolvimento das habilidades cognitivas, mas também o desenvolvimento das habilidades socioemocionais.

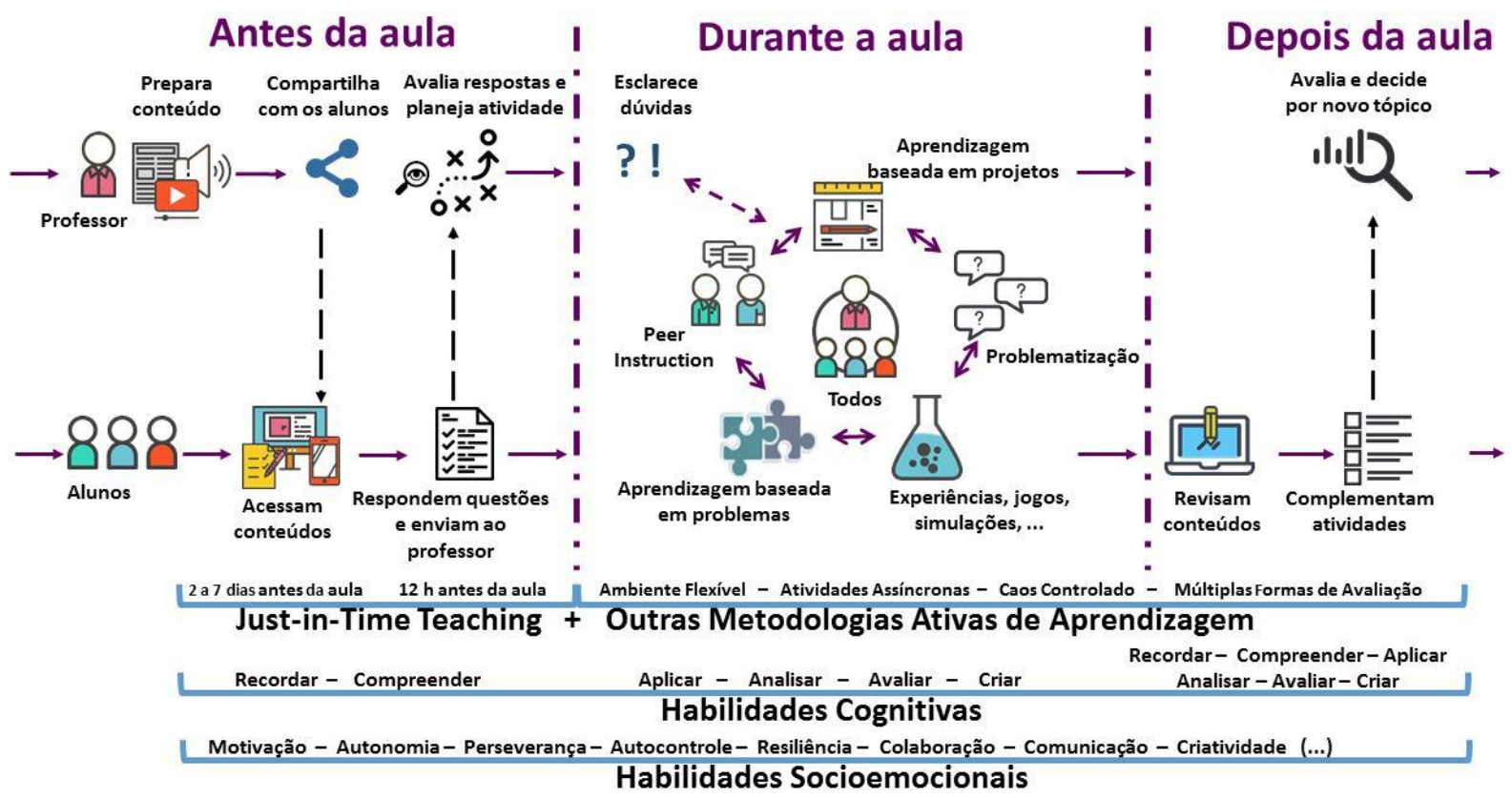

FIGURA 2 - Integração do modelo da sala de aula invertida com metodologias ativas Fonte: Schmitz (2016, p. 80)

O esquema proposto, na Figura 2, apresentado aos docentes da pesquisa realizada por Schmitz (2016), buscou dar visibilidade à abordagem da sala de aula invertida, de modo a contribuir para o melhor entendimento de como o professor pode planejar e implementar a inversão, usando uma ou várias metodologias. De acordo com Bergmann e Sams (2016), como não existe um modelo único de inversão, em aula, o professor pode guiar atividades práticas diferentes ou possibilitar que alunos trabalhem, em grupos ou individualmente, em tarefas diferentes simultaneamente ou, ainda, que sejam avaliados quando se sentirem preparados. Na sequência, descreve-se a metodologia adotada na presente investigação. 


\section{MÉTODO}

Para realizar a presente pesquisa, recorreu-se a uma metodologia de abordagem qualiquantitativa, descritiva, exploratória e bibliográfica para a produção do material didático instrucional ${ }^{7}$. A partir do material digital proposto para a pesquisa, foi averiguada a compreensão dos conceitos básicos apresentados sobre a teoria, bem como a descrição do grau de familiaridade com a temática e a identificação das necessidades de formação para a aplicação da SAI no contexto universitário A pesquisa teve como público-alvo os 1.972 docentes da UFSM, sendo que efetivamente responderam ao questionário 79 docentes ${ }^{8}$. Optou-se por disponibilizar o material didático e o instrumento de pesquisa de forma eletrônica, pelo sistema de questionário do Centro de Processamento de Dados (CPD), onde ficou disponível para resposta, no Portal do Professor, pelo período de 26 dias (de 5 de setembro de 2016 a 30 de setembro de 2016). Assegurou-se autonomia aos sujeitos para aceite do Termo de Consentimento Livre e Esclarecido e acesso ao conteúdo didático, bem como para desistência de sua participação a qualquer momento. A elaboração do instrumento de coleta seguiu os eixos temáticos descritos no Quadro 1.

A representatividade da amostra em relação à população foi averiguada pelo Teste Qui-quadrado de Aderência, por meio do pacote estatístico SPSS, versão 18.0, com nível de significância de 5\%. A referência para o estudo das respostas às questões abertas foi a abordagem da análise de conteúdo (BARDIN, 1979).

\footnotetext{
${ }^{7}$ Esse material (vídeo e pdf interativo) encontra-se no repositório institucional disponível online em htttp://ntetube.nte.ufsm/v/1469799357

${ }^{8}$ Cada docente participante foi identificado como professor-participante, seguido de um número X (PP-X), preservando-se o anonimato.
} 
Resultados do TC

O TC sobre sala de aula invertida teve por objetivo verificar a compreensão dos conceitos e conteúdos apresentados no material didático instrucional (vídeo e pdf interativo), bem como identificar dúvidas e dificuldades que os participantes encontraram no material. Cabe lembrar que o instrumento de pesquisa orientou o participante a visualizar o material didático antes de efetuar o TC. Portanto, a primeira questão do TC teve por finalidade verificar, em linhas gerais, a abstração do significado de inverter a sala de aula e a segunda questão pretendia verificar a identificação, pelos sujeitos respondentes, de dois componentes-chave do modelo da sala de aula invertida, ou seja, a tecnologia educacional e as atividades de aprendizagem.

Essas duas primeiras questões do TC apresentaram $83,5 \%$ e $87,3 \%$ de acertos, percentual superior em relação ao da questão seguinte que obteve $72,2 \%$ de acertos, conforme ilustra a Figura 3. Acredita-se que isso se deu em razão de a referida pergunta possuir um grau de complexidade maior em sua elaboração, de modo a exigir do participante mais atenção durante a leitura e a visualização dos conteúdos apresentados no material didático, demandando também um grau mais apurado de análise e interpretação.

Com isso, considerou-se que os resultados do TC analisados, com o objetivo de averiguar a compreensão dos conceitos básicos apresentados, esclarecem que a maioria dos pesquisados leu e interpretou corretamente os conteúdos do material didático, já que o percentual de acertos das três primeiras questões ficou acima de $70 \%$. Isso demonstra, ainda, que houve boa interação direta dos participantes com os conteúdos propostos no material digital.

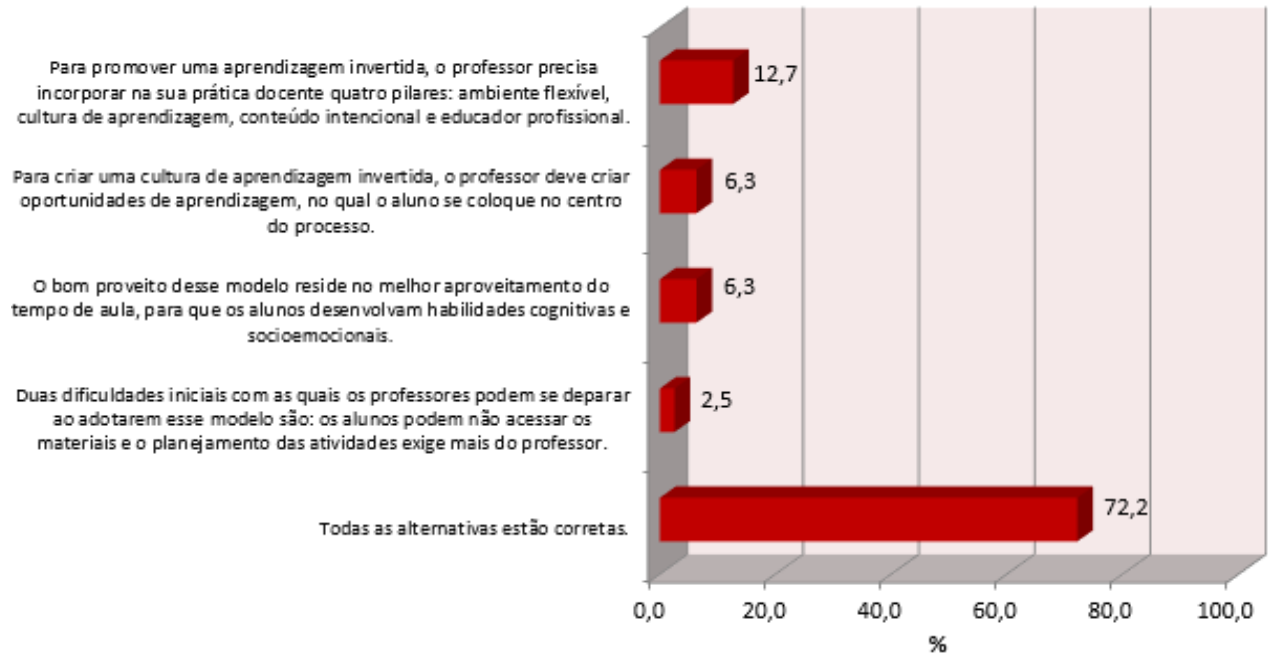

FIGURA 3 - Distribuição de respostas sobre o que é correto afirmar acerca da sala de aula invertida Fonte: Schmitz (2016, p. 101).

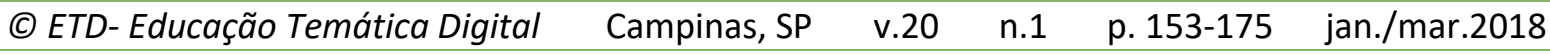


A última questão do TC abriu espaço para o registro de dúvidas ou dificuldades de entendimento dos participantes. As dúvidas mais significativas foram sobre: (i) metodologias usadas na confecção de material a ser disponibilizado na SAI (PP-3); (ii) quantidade ideal de alunos por turma (PP-21); (iii) relação custo-benefício, no que diz respeito a tempo e dedicação necessários para a implementação do modelo (PP-19); (iv) preocupação em como por em prática ou como aplicar o modelo como um todo (PP-11) e (v) como engajar alunos (PP-7; PP-8; PP-15).

Com relação à dúvida sobre quais metodologias usar na confecção do material a ser disponibilizado, de fato, não é tarefa fácil encontrar referencias teóricos sobre o assunto, ainda mais quando é importante, segundo Bergmann e Sams (2016), que o professor elabore, disponibilize e garanta o acesso aos materiais por parte dos alunos, o que pode demandar o uso de diferentes mídias e conhecimentos específicos na elaboração dos materiais. Nesse sentido, os autores dão destaque para a área do design instrucional, mais especificamente, sobre a teoria do Desenho Universal para a Aprendizagem (Universal Design for Learning - UDL) que tem por princípios básicos oferecer vários meios de representação, de expressão e de engajamento. Assim, instituições que contam com profissionais da área de design instrucional, como é o caso do Núcleo de Tecnologia Educacional da UFSM, podem assessorar os docentes na produção de materiais. Além disso, Mallmann ressalta que

\footnotetext{
A transposição didática por natureza é um processo que requer ação criativa. A transposição dos saberes sábios em saberes a ensinar e ensinados ultrapassa a representação do papel de atores/autores. Todo ato criativo docente, tal como elaborar material didático para mediação pedagógica, antecipar estratégias de ensino-aprendizagem, atividades de avaliação, requer o privilégio da performance. (MALLMANN, 2008, p. 27)
}

Quanto à dúvida sobre o tamanho do grupo, em geral, a decisão sobre o número de alunos por turma está fora da governabilidade do professor e depende mais de questões políticas e administrativas da instituição de ensino. Entretanto, o que se pode dizer sobre esse assunto é o que aponta o estudo de Danker (2015), em que o autor sugere que o tamanho da turma não é fator preponderante para a inversão da sala de aula, pois, mesmo em turmas grandes, em se tratando de um ensino ativo, o aluno encontra e ocupa o seu lugar em sala de aula.

No que diz respeito à relação custo-benefício, Christensen, Horn e Staker (2013) afirmam que a SAl é o modelo mais simples para dar início à implantação do ensino híbrido, dependendo apenas de um bom planejamento dos professores. Para Carvalho e McCandless (2014), o sucesso do modelo depende da preparação do corpo docente e discente e da infraestrutura. Assim, a instituição precisa preparar os professores, saber lidar com as resistências e garantir apoio tecnológico e de infraestrutura. Segundo estudo realizado por

$\begin{array}{llllll}\text { (C) ETD-Educação Temática Digital } & \text { Campinas, SP } & \text { v.20 } & \text { n.1 } & \text { p. 153-175 } & \text { jan./mar.2018 }\end{array}$


esses autores, embora a SAI necessite de planejamento, formação e investimento financeiro, os benefícios superam os custos, uma vez que a estratégia facilitou as interações e promoveu a participação ativa discente. Além disso, as palestras online, seguidas por sessões de aprendizagem ativa em aula, agradaram alunos e professores.

Quanto à preocupação em como pôr em prática ou como aplicar o modelo como um todo, não há um modelo único para inverter a sala de aula, contudo a busca por experiências nessa área passa por características como: o acesso com antecedência ao conteúdo; a competência do educador em entender os estudantes e o aprendizado de ordem superior no tempo de sala de aula (O'FLAHERTY; PHILLIPS, 2015; BERGMANN; SAMS, 2016), ou seja, atividades que envolvam as formas mais elevadas de trabalho cognitivo da Taxonomia revista de Bloom: "aplicar, analisar, avaliar e criar" (TEIXEIRA, 2013, p. 15). Como não há um modelo único de inversão, em aula, o professor pode planejar atividades práticas diferentes ou possibilitar que os alunos trabalhem, em grupo ou individualmente, em tarefas diversas, simultaneamente e que sejam avaliados quando se sentirem preparados para isso. (BERGMANN; SAMS, 2016, p. 45).

A dúvida quanto ao engajamento vai ao encontro das discussões encontradas na revisão de literatura, as quais demostram que o engajamento de alunos e de professores é um dos pontos-chave para o sucesso da aplicação da SAI. Estudos sobre como engajar alunos nas atividades de classe sugerem que a alternativa é preparar aulas sob medida e diversificar as atividades em aula, intercalando e combinando métodos (NOVAK et al., 1999; CROUCH; MAZUR, 2001; ARAUJO; MAZUR, 2013). Carvalho e McCandless (2014) ressaltam, entre outros aspectos, a importância da preparação do corpo docente e acadêmico, uma vez que é preciso explicar aos alunos como funciona a sala de aula invertida para que a implementação da abordagem seja bem-sucedida.

É preciso, ainda, conforme salientam Bergmann e Sams (2016, p. 76) preparar os alunos para que façam perguntas "interessantes" sobre os materiais disponibilizados, ou seja, "a pergunta deve se relacionar com o vídeo e de fato expressar uma dúvida". Por isso, os autores orientam os alunos a usarem o método Cornell de anotações: transcrever pontos importantes, registrar dúvidas e resumir o conteúdo. "As perguntas que fazem [os alunos] geralmente revelam equívocos e indicam o que não lhes ensinamos com clareza" (BERGAMANN; SAMS, 2016, p. 76). Além disso, segundo os autores, dúvidas semelhantes sobre a informação disponibilizada evidenciam que a abordagem não foi adequada, indicando necessidade de correção e melhoria. 
Autorreflexão sobre o grau de informação do participante

Em duas questões propostas no questionário, os sujeitos foram convidados a refletir sobre o quanto se sentiam informados e o quanto passaram a se sentir informados após contato com o material didático e a realização do TC. Os dados mostram um aumento considerável no grau de informação depois da interação com o material e a conclusão do TC. Antes de participar da pesquisa, os que se consideravam "muito, razoavelmente, pouco e nada informados" eram, respectivamente, um (1,3\%), $17(21,5 \%), 37(46,8 \%)$ e $24(30,4 \%)$. Após a pesquisa, os que se consideravam "muito, razoavelmente, pouco e nada informados" passaram a ser, respectivamente, 15 (19\%), 50 (63,3\%) e 14 (17,7\%) e zero. Esses dados, bem como os do TC evidenciam que houve interação dos participantes com o conteúdo e sugerem que o material didático instrucional serviu como termo de referência para informar os participantes.

\section{Experiência}

Ao questionar os participantes sobre experiências prévias com sala de aula invertida, de modo a identificar quais aspectos da abordagem os docentes afirmam usar (Figura 4) e quais metodologias aplicam em sala de aula, os resultados mostram que os docentes preparam e distribuem conteúdo em diferentes formatos para acesso dos alunos antes das aulas $(65,8 \%)$ e que usam o tempo em aula para atividades práticas e feedback imediato (78, $5 \%)$. Conclui-se, porém, que a estratégia é aplicada de modo parcial, pois o planejamento das atividades de aula não é feito com base nas dúvidas e nas respostas dos alunos em uma etapa pré-classe. Isso leva a crer que o processo de ensino-aprendizagem ainda se encontra muito centrado no docente, uma vez que os percentuais de marcações mais baixos foram para as alternativas que se referem ao planejamento, ou seja, o "planejamento das atividades de aula, com base nas respostas e dúvidas dos alunos em uma etapa pré-classe" $(31,6 \%)$ e o "planejamento de atividades assíncronas a serem realizadas pelo aluno no tempo de aula" $(35,4 \%)$, o que sugere que a proposta pedagógica não tem por foco a personalização da aprendizagem. 


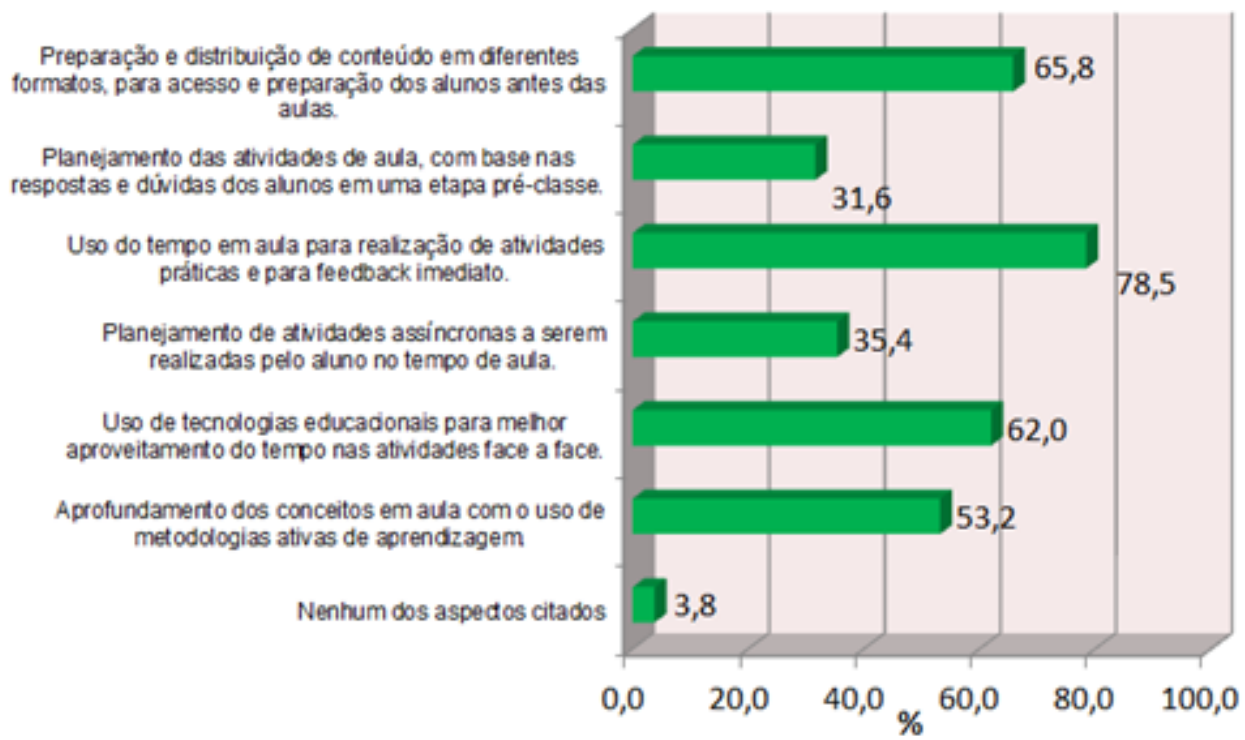

FIGURA 4 - Aspectos da abordagem da sala de aula invertida que os docentes afirmam usar Fonte: Autor 1 (2016, p. 111).

Acerca de quais metodologias ou estratégias de ensino-aprendizagem o docente aplica ou já aplicou em sala de aula, os itens mais assinalados pelos docentes foram "Aprendizagem Baseada em Problemas (ABP)", 55,7\%, "Problematização", 54,4\% e "Experimentações", 51,9\%. O fato de as metodologias ABP e problematização terem recebido maior número de marcações suscita a necessidade de estudos investigativos mais aprofundados, uma vez que é preciso verificar se não houve confusão entre os dois termos apresentados, bem como identificar os cursos da instituição que empregam a metodologia ABP. Já os itens que receberam menos marcações foram "Sala de aula invertida", 17,7\%.

No espaço destinado para o participante complementar sua resposta, a análise do conteúdo dos registros mostrou que os professores se detiveram em relatar as suas práticas docentes, nas quais foram identificados o fornecimento prévio de materiais aos alunos e o uso do tempo em sala para atividades como "apresentação e debate" (pelos alunos), "júri simulado" e "Fórum de notícia no Moodle", "oficinas de leitura crítica" e de "leitura complementar", "atividades nas quais os alunos devem preparar aulas teóricas e experimentais", atividades de "síntese de conteúdos, de problemas e de aplicações [...]". Pontualmente, foram citados pelos participantes o uso de "Portfólio de aprendizagem. 0 que vem dando resultados, até o momento, bastante satisfatórios" e o uso de "Atividades de estudo". Observa-se, pelo conteúdo das narrativas, que alguns docentes quiseram usar o espaço para compartilhar, de forma detalhada, suas experiências. Esse fato indica a necessidade de que sejam criados espaços institucionais para o compartilhamento de informações, nesse ínterim, promover espaços de interação, sem que seja presencialmente,

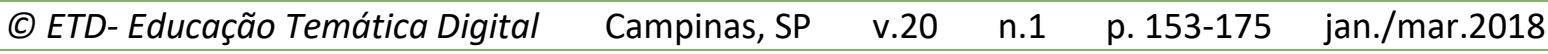


para docentes compartilharem suas práticas, amplia as bases de ensino e deve ser planejada pelas instituições (KENSKI, 2013).

\section{Necessidades}

Outras duas questões no questionário tiveram por objetivo identificar necessidades de formação, mais especificamente sobre quais metodologias ou estratégias de ensino [os professores] gostariam de usar para inverter a sala de aula, mas não sabem. Os itens mais marcados foram Peer Instruction (PI) ou Instrução pelos Colegas (IPC), 60,8\% (48), Just-inTime Teaching (JiTT) ou Ensino sob Medida (EsM), 53,2\% (42) e Jogos, 36,7\% (29). 0 interesse pelo uso do PI e do JiTT confirma a análise de Araujo e Mazur (2013) sobre o fato de esses métodos não serem muito conhecidos no Brasil e mostra que o conteúdo apresentado despertou interesse dos participantes. Ainda, os dados dessa pergunta são coerentes com os resultados sobre as metodologias e estratégias que os docentes já aplicam, pois são exatamente as menos utilizadas, na indicação dos participantes: "PI ou IpC", 6,3\% (5), "JiTT ou EsM", 5,1\%, (4) e "Jogos", 24,1\% (19). Os que complementaram a sua resposta fizeram referência à "sala de aula invertida", ao "chat no Moodle e ou possibilidade de usar o Skype no Moodle" e, ainda, a: "qualquer metodologia para evitar a passividade dos alunos", "principalmente para a avaliação de aprendizagem" e "ensinoaprendizagem baseados em On Line Inquiry".

Com relação à avaliação, Bergamnn e Sams (2016, p. 52) exploram a tecnologia para resolver o problema dos muitos testes necessários para a adoção do modelo de aprendizagem invertida para o domínio (Taxonomia revista de Bloom). Portanto, afirmam que as avaliações são administradas por intermédio de computadores, a partir da criação de um banco de questões, por meio do módulo de questionários do Moodle. Os resultados das questões vistas até aqui evidenciam o interesse dos participantes por metodologias ativas de aprendizagem. Sobre quais tecnologias educacionais o professor gostaria de usar para inverter a sala de aula e não sabe, sendo permitido marcar todas as opções que se aplicavam. Os itens mais assinalados foram, em primeiro lugar, a "Lousa digital interativa", 53,2\%, em segundo, "Software de edição de vídeo/áudio", 51,9\%, em terceiro, "Screencast", $50,6 \%$, e, em quarto, "Podcast", 46,8\%. Já os itens menos assinalados foram "Redes sociais" e "Formulário do Google", com 16,5\% e 24,1\%, respectivamente. Esses dados reforçam o estudo de Barbosa et al. (2014) a respeito do uso das TIC pelos professores da instituição, em 2013. Isso demonstra que há ainda muita demanda por formação sobre o uso dessas tecnologias e que elas continuam sendo apontadas como uma necessidade de formação pelos docentes. Os respondentes que complementaram sua resposta fizeram referência ao desejo de: aprender mais sobre as funcionalidades do Moodle; fazer "Experimentação remota" e usar ferramentas que não necessitam de internet para locais com pouca infraestrutura.

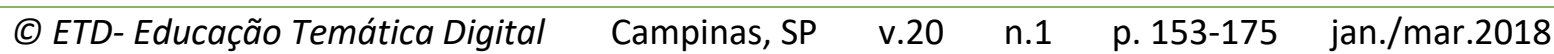


Esse relato indica que, em algumas localidades da universidade, o funcionamento da rede deixa a desejar. Ainda sobre essa questão, um participante escreveu "Mais uma vez qualquer outra que retire os alunos da passividade", o que demostra preocupação com o ensino e com o engajamento dos alunos. Um docente declarou necessidade de "Mais interação pessoal e menos tecnologia" e outro afirmou que não tem "problemas com as tecnologias citadas". A respeito das respostas dos sujeitos, é interessante observar o contraste demonstrado entre o desejo de um respondente em usar telepresença (experimentação remota) e o de outro, que espera explorar mais a interação pessoal, com menos tecnologia. Os comentários e os percentuais superiores a $40 \%$ a respeito das tecnologias que os docentes querem usar refletem o desejo dos docentes em aumentar a interação mediada pelos recursos tecnológicos com os alunos e em diminuir a passividade dos estudantes, bem como indicam uma diversidade de interesse pelas novas ferramentas disponíveis.

Ao ser questionado sobre "quais áreas temáticas, assuntos e conteúdos [o participante] indicaria como uma necessidade de formação para aplicação da sala de aula invertida na sua prática docente?", podendo assinalar mais de uma opção, os assuntos indicados foram: em primeiro lugar, "Metodologias Ativas de Aprendizagem", 68\%, em segundo, "Ensino Híbrido", 54,4\%, em terceiro, empatados com 53,3\%, "Tecnologia Educacional" e "Roteirização de Videoaulas", e, em quarto, "Noções de Produção Audiovisual" 50,6\%. Mais uma vez, transparece o desejo por interação e uso de tecnologias e o interesse pelas estratégias e métodos apresentados. Os resultados indicam, assim, que a temática chamou a atenção e o interesse dos professores participantes para as estratégias de ensino apresentadas. Os participantes que complementaram sua resposta demonstraram preocupação com a formação pedagógica para atuarem como professores no ensino superior. Os comentários mostraram não só a preocupação com o aprender a ensinar, mas revelaram, também, um contexto de ausência de formação e preparação do professor universitário no que se refere aos saberes metodológicos para o exercício do magistério superior, especialmente, para uma parcela de profissionais que não possui formação em licenciatura:

Tudo que desconheço e gostaria de aprender nesta área. (p-24) Dependendo da formação do docente, não tivemos disciplinas relacionadas à pedagogia, licenciatura. Muitas vezes somos docentes, e aprendemos "na raça", na marra. Há necessidade de cursos constantes de atualização de metodologias e estratégias de ensino nas mais diversas áreas do conhecimento. Pois um fator importante é a aplicação, como por exemplo, da aula invertida dentro da Engenharia. ( $p-11)$ 
Os aspectos da formação docente observados acima também foram observados em questão aberta proposta e que se citou nessa etapa de discussão por ser mais oportuno para análise, pois o conteúdo elucida os aspectos problemáticos da formação pedagógica dos professores, na pós-graduação, com menção à falta de preparação para dar aulas; à questão de os professores serem ou não "sortudos" quanto à assistência de seus orientadores; à necessidade de desenvolverem seus métodos de ensino na "marra", mesma expressão usada anteriormente. $\mathrm{O}$ tempo foi apontado como principal dificuldade por um participante para estudo de novos métodos e aprimoramento do ensino na graduação, além de que isso implicaria na quebra de paradigma, já que envolve tirar o docente da zona de conforto, fazendo com que ele dedique menos tempo à pesquisa ou, então, levando-o a trabalhar mais de 40 horas. Na opinião de Morosini (2000), Pimenta e Anastasiou (2002) e Masetto (2006), as instituições dedicam pouca atenção à formação e à preparação pedagógica do professor universitário para o exercício da atividade docente:

Na maioria das instituições de ensino superior, incluindo as universidades, embora seus professores possuam experiência significativa e mesmo anos de estudos em suas áreas específicas, predomina o despreparo e até um desconhecimento científico do que seja o processo de ensino e de aprendizagem. (PIMENTA; ANASTASIOU, 2002, p. 37).

Isso ocorre, segundo os autores, porque há certo consenso de que, no ensino superior, não é preciso formação no campo do ensinar, uma vez que é incontestável a longa história de estudos, formação e reconhecimento dos docentes nas suas áreas específicas de conhecimento. Como, então, o professor universitário de áreas distintas da licenciatura aprende a ensinar? Os comentários supracitados indicam a resposta: "na raça", "na marra". Ou seja, o profissional aprende fazendo, pela prática e trajetória docente, com o acumulo de experiências, dos "saberes experienciais" (TARDIF, 2002, p. 48), conforme sugere o trecho de outro participante que diz: "Fui montando a metodologia para estas aulas, juntando e adaptando experiências com o correr dos anos na docência (...)".

As declarações dos professores participantes podem indicar, também, o percurso solitário em que muitos se encontram no processo de aprender a ensinar, não tendo, muitas vezes, com quem dividir êxitos e angústias (VASCONCELOS, 2006, p. 77), embora nunca atuem sozinhos, pois se encontram "em interação com outras pessoas, a começar pelos alunos" (TARDIF, 2002, p. 49). Muitos dos relatos vistos até aqui mostram também a importância das declarações e narrativas docentes, uma vez que, por meio delas, é possível conhecer o ensino, os saberes, as práticas, os dilemas, as necessidades e o eu profissional, que, segundo Nóvoa (1995), não se pode separar do eu pessoal: 
Ei-nos de novo face à pessoa e ao profissional, ao ser e ao ensinar. Aqui estamos. Nós e a profissão. E as opções que cada um de nós tem de fazer como professor, as quais cruzam a nossa maneira de ser com a nossa maneira de ensinar e desvendam na nossa maneira de ensinar a nossa maneira de ser. É impossível separar o eu profissional do eu pessoal. (NÓVOA, 1995, p. 17).

Autores como Nóvoa (1995), Tardif (2002) e outros dedicam atenção às narrativas autobiográficas dos docentes para estudos sobre as dimensões pessoais e profissionais, a reflexão entre a ação e o saber dos professores e as perspectivas metodológicas de uso das narrativas como, por exemplo, para a investigação da prática educativa, pois, como acredita Nóvoa (1995, p. 25), "pelas histórias de vida, pode passar a elaboração de novas propostas sobre a formação de professores e sobre a profissão docente". Contudo, como muito bem destaca Moita (1995, p. 117), "cada história de vida, cada percurso, cada processo de formação é único. Tentar elaborar conclusões generalizadas seria absurdo".

Behrens (2006, p. 61-65) afirma que os gestores de departamento e centros de ensino precisam não só buscar docentes com titulação, mas oferecer preparação pedagógica aos professores para a atuação em aula. Destaca, ainda, que as instituições precisam ampliar ofertas de especialização na área pedagógica, possibilitar formação continuada e propor projetos que envolvam os professores em grupos de estudo, trabalho individual e coletivo. De acordo com o autor, as dificuldades em mobilizar e envolver os docentes decorrem do próprio meio acadêmico, que enfatiza a qualificação docente na titulação, na pesquisa e na produção científica. Para ele, é função dos "[...] gestores das instituições de ensino superior, e em especial aos pedagogos, oferecer uma formação continuada aos professores, uma formação que os aproxime dos paradigmas inovadores [...]" (BEHRENS, 2006, p. 67).

\section{CONSIDERAÇÕES FINAIS}

Os resultados do TC e os comentários dos participantes, externando apreciação ao material didático e à temática demonstram, em linhas gerais, que houve compreensão dos conceitos apresentados, indicam boa interação direta dos participantes com o recurso educacional, evidenciando que o mesmo foi capaz de promover uma reflexão nos participantes sobre a própria prática docente. Constatou-se, também, que a abordagem da sala de aula invertida era desconhecida da maioria dos participantes e que alguns aspectos da abordagem são aplicados pelos professores nas práticas pedagógicas, embora de forma parcial. Os participantes demonstraram interesse em aprender metodologias ativas de aprendizagem e tecnologias educacionais que aumentem o engajamento de alunos. A indicação pelos participantes de necessidade de formação em softwares de edição de áudio/vídeo, screencast e podcast e por assuntos relacionados à produção audiovisual, confirma uma tendência crescente em educação pela produção e uso de materiais multimídia (SCHMITZ, 2016).

$\begin{array}{llllll}\text { (C) ETD- Educação Temática Digital } & \text { Campinas, SP } & \text { v.20 } & \text { n.1 } & \text { p. 153-175 } & \text { jan./mar.2018 }\end{array}$


Os resultados da pesquisa permitiram o desenho de um panorama inicial sobre as abordagens metodológicas em uso no contexto da UFSM e as demandas por formação docente, especialmente, no que diz respeito às temáticas da atualidade como, por exemplo, sobre metodologias ativas, ensino híbrido e personalização do ensino. Esses dados contribuem para o planejamento de ações institucionais de formação e de capacitação continuada dos docentes, de modo a instigar a adoção de modelos de aplicação de ensinoaprendizagem que combinem diferentes metodologias de aprendizagem e tecnologias, melhorando o engajamento de alunos no processo de ensino-aprendizagem.

Por fim, conclui-se também que a disponibilização de materiais didáticos autoinstrucionais pode contribuir para a formação continuada de professores e consequentemente para inovação dos processos de ensino-aprendizagem no contexto universitário. O material didático, por apresentar esquemas de modelagem da sala de aula invertida, além de conceitos, dicas, exemplos de atividades e de integração às metodologias ativas de aprendizagem, mostrou potencial de reusabilidade, podendo ser usado pelo professor em sala de aula para explicar aos alunos a forma de trabalho (de ensino) e o modelo de inversão da sala de aula.

\section{REFERÊNCIAS}

SCHMITZ, Elieser Xisto da Silva Schmitz. Sala de aula invertida: uma abordagem para combinar metodologias ativas e engajar alunos no processo de ensino-aprendizagem. 2016. 185 p. Dissertação (Mestrado Profissional em Tecnologias Educacionais em Rede ) Universidade Federal de Santa Maria , Santa Maria, RS,, 2016.

ANDRADE, Hugo Sica de; LOBATO, Luanna Lopes. Uma discussão sobre métodos sistemáticos para revisão de trabalhos científicos em engenharia de software. In: ENCONTRONACIONAL DE COMPUTAÇÃO, 8., 2010, Catalão/GO. Anais [...] Goiânia: UFG, 2010.

ARAUJO, Ives Solano; MAZUR, Eric. Instrução pelos colegas e ensino sob medida: uma proposta para engajamento dos alunos no processo de ensino-aprendizagem de física. Caderno Brasileiro de Ensino de Física, Florianópolis, v. 30, n. 2, p. 362-384, 2013.

BARBOSA, Fernando Pires et al. Planejamento de TI em universidades: relato dos primeiros dois anos de trabalho com PDTI e práticas de Gestão de Serviços. In: WORKSHOP DE TECNOLOGIA DA INFORMAÇÃO E COMUNICAÇÃO DAS IFES, 8., 2014, Brasília/DF. Anais [...] Brasília: Colégio de Gestores de Tecnologia da Informação e Comunicação das IFES, 2014.

BARDIN, Laurence. Análise de conteúdo. Tradução de Luís Antero Reto e Augusto Pinheiro. Lisboa: Edições 70, 1977.

BACICH, Lilian.; TANZI NETO, Adolfo; TREVISANI, Fernando de Mello. (Org.). Ensino híbrido: personalização e tecnologia na educação. Porto Alegre: Penso, 2015.

$\begin{array}{llllll}\text { (C) ETD- Educação Temática Digital } & \text { Campinas, SP } & \text { v.20 } & \text { n.1 } & \text { p. 153-175 } & \text { jan./mar.2018 }\end{array}$


BEHRENS, Marilda Aparecida. A formação pedagógica e os desafios do mundo moderno. In: MASETTO, Marcos Tarciso. (Org.). Docência na Universidade. 8. ed. Campinas, São Paulo: Papirus, 2006. p. 57-76.

BERGMANN, Jon; OVERMYER, Jerry; WILIE, Brett. The flipped class: what it is and what it is not. The Daily Riff, [S.I.], Jul. 9, 2013.

BERGMANN, Jon.; SAMS, Aaron. Flip your classroom: reach every student in every class every day. [S.I]: ISTE; ASDC, 2012.

BERGMANN, Jon; SAMS, Aaron. Sala de aula invertida: uma metodologia ativa de aprendizagem. Tradução de Afonso Celso da Cunha Serra. Rio de Janeiro: LTC, 2016.

CARVALHO, Helena; MCCANDLESS, Margarite. Implementing the flipped classroom. Revista Hupe, Rio de Janeiro, v. 13, n. 4, p. 39-45, out-dez. 2014.

CHRISTENSEN, Clayton M.; HORN, Michael B.; STAKER, Heather. Ensino híbrido: uma inovação disruptiva? Uma introdução à teoria dos híbridos. Traduzido por Fundação Lemann e Instituto Península. [S.I.: s.n.], 2013.

CROUCH, Catherine H.; MAZUR, Eric. Peer instruction: ten years of experience and results. American Journal of Physics, Melville, v. 69, n. 9, p. 970-977, 2001.

DANKER, Brenda. Using flipped classroom approach to explore deep learning in large classrooms. The IAFOR Journal of Education, Nagoya, v. 3, n. 1, p. 171-186, 2015.

FLIPPED Classroom Field Guide [Internet]. [S.I.: s.n], [201-]. Disponível em: https://docs.google.com/document/d/1arP1QAkSyVcxKYXgTJWCrJf02NdephTVGQItswS1fQ/view. Acesso em: 13 dez. 2015.

FLIPPED LEARNING NETWORK. Definition of flipped learning [Internet]. South Bend, IN: Flipped Learning, 2014. Disponível em: http://www.flippedlearning.org/domain/46. Acesso em: 20 out. 2015.

KENSKI, Vani Moreira. Tecnologias e tempo docente. Campinas: Papirus, 2013.

LAGE, Maureen J.; PLATT, Glenn J.; TREGLIA, Michael. Inverting the classroom: a gateway to creating an inclusive learning environments. Journal of Economic Education, Bloomington, v. 31 , n. 1, p. 30-43, 2000.

LOPES, Áurea. O jeito de aprender já mudou: falta mudar o jeito de ensinar. In: BIT SOCIAL. 70 Anuário ARede 2015-2016: boas práticas de tecnologias na educação. São Paulo: Laser Press, 2015. p. 6-7.

MALLMANN, Elena Maria. Mediação pedagógica em educação a distância: cartografia da performance docente no processo de elaboração de materiais. 2008. $304 \mathrm{f}$. Tese (Doutorado em Educação) - Universidade Federal de Santa Catarina, Florianópolis, Santa Catarina, 2008.

$\begin{array}{llllll}\text { (C) ETD- Educação Temática Digital } & \text { Campinas, SP } & \text { v.20 } & \text { n.1 } & \text { p. 153-175 } & \text { jan./mar.2018 }\end{array}$


MARGULIEUX, Lauren; MAJERICH, David; MCCRACKEN, Mike. C21U's guide to flipping your classroom. Atlanta: Georgia Institute of Technology, 2013.

MASETTO, Marcos Tarciso. (Org.). Docência na universidade. 8. ed. Campinas: Papirus, 2006.

MAZUR, Eric; WATKINS, Jessica. Using JiTT with peer instruction. In: SIMKINS, Scott; MAIER, Mark. Just-in-time teaching: across the disciplines, and across the academy. Sterling: Stylus Publishing, 2009. p. 39-62.

MIRANDA, Luísa Augusta Vara. Educação online: interacções e estilos de aprendizagem de alunos do ensino superior numa plataforma web. 2005. $382 \mathrm{f}$. Tese (Doutorado em Educação) - Universidade do Minho, Braga, 2005.

MOITA, Maria da Conceição. Percursos de formação e de trans-formação. In: NÓVOA, António Sampaio da. Vidas de professores. Porto: Porto, 1995. p. 111-118.

MORAN, José Manuel. Mudando a educação com metodologias ativas. In: SOUZA, Carlos Alberto de; TORRES-MORALES, Ofelia Elisa. (Org.). Convergências midiáticas, educação e cidadania: aproximações jovens. Ponta Grossa: UEPG, 2015. (Mídias Contemporâneas, v. 2). p. 15-33.

MOROSINI, Marília Costa. Docência universitária e os desafios da realidade nacional. In: MOROSINI, Marília Costa. (Org.). Professor do ensino superior: identidade, docência e formação. 2. ed. Brasília: Plano Editora, 2000. p. 11-20.

NOVAK, Gregor M. et al. Just-in-time teaching: blending active learning with web technology. Upper Saddle River: Prentice Hall, 1999.

NÓVOA, António Sampaio. Os professores e as histórias da sua vida. In: NÓVOA, António Sampaio. (Org.). Vidas de professores. Porto: Porto Editora, 1995. p. 11-30.

O'FLAHERTY, Jacqueline; PHILLIPS, Craig. The use of flipped classrooms in higher education: a scoping review. The Internet and Higher Education, New York, n. 25, p. 85-95, apr. 2015.

OLIVEIRA, Vagner; VEIT, Eliane Angela; ARAUJO, Ives Solano. Relato de experiência com os métodos de ensino sob medida (just-in-time teaching) e instrução pelos colegas (peer instruction) para o ensino de tópicos de eletromagnetismo no nível médio. Caderno Brasileiro de Ensino de Física, Florianópolis, v. 32, n. 1, p. 180-206, abr. 2015.

PIMENTA, Selma Garrido; ANASTASIOU, Léa das Graças Camargos. Docência no ensino superior. São Paulo: Cortez, 2002.

PRADO, Ana. Entendendo o aluno do século 21 e como ensinar a essa nova geração. São Paulo: Geekie, 2015.

PRENSKY, Marc. Changing paradigms: from "being taugh" to "learning in your own with guidance". Educational Technology, [S.I], p. 1-3, 2007.

$\begin{array}{llllll}\text { (C) ETD- Educação Temática Digital } & \text { Campinas, SP } & \text { v.20 } & \text { n.1 } & \text { p. 153-175 } & \text { jan./mar.2018 }\end{array}$


RAMAL, Andrea. Sala de aula invertida: a educação do futuro. G1 Educação, Rio de Janeiro, 28 abr. 2015. Disponível em: http://g1.globo.com/educacao/blog/andrea-ramal/post/salade-aula-invertida-educacao-do-futuro.html ._Acesso em: 25 out. 2015.

RODRIGUES, Carlos Eduardo Serrina de Lima. Habilidades socioemocionais: a OCDE e seu projeto de governança educacional global. In: REUNIÃO NACIONAL DA ANPED, 37., 2015, Florianópolis/SC. Anais... Florianópolis: UFSC, 2015. Disponível em:

http://37reuniao.anped.org.br/wp-content/uploads/2015/02/Trabalho-GT13-4316.pdf . Acesso em: 24 out. 2015.

SAMS, Aaron. The flipped class: shedding light on the confusion, critique, and hype. The Daily Riff, nov. 11, 2011.

TARDIF, Maurice. Saberes docentes e formação profissional. Petrópolis, RJ: Vozes, 2002.

VALENTE, José Armando. Blended learning e as mudanças no ensino superior: a proposta da sala de aula invertida. Educar em Revista, Curitiba, n. 4, p. 79-97, 2014.

TEIXEIRA, G. P. Flipped classroom: um contributo para a aprendizagem da lírica camoniana. 2013. 167 f. Dissertação (Mestrado em Gestão de Sistemas de E-Learning) - Universidade Nova Lisboa, Lisboa, Portugal, 2013.

VASCONCELOS, Maria Lúcia Marcondes Carvalho. Contribuindo para a formação de professores universitários: relato de experiências. In: MASETTO, Marcos Tarciso. Docência na universidade. 8. ed. Campinas: Papirus, 2006. p. 77-93.

\section{Agradecimentos}

A todos que, durante a trajetória deste estudo, tornaram-se parceiros, colaboradores, amigos e contribuíram para o desenvolvimento deste trabalho, em especial, ao Núcleo de Tecnologia Educacional da UFSM e a Carlos André Aita Schmitz, professor da Universidade Federal do Rio Grande do Sul (UFRGS), por sua ativa participação e valorosas contribuições.

\footnotetext{
'Revisão: Rosely de Andrade Vargas - e-mail: Rosely.vargas@telessauders.ufrgs.br
} 